\title{
APROXIMACIONES AL ESPECTÁCULO DEPORTIVO Y AÑORANZAS DE PEDAGOGÍA
}

\section{Por: Ricardo Alexis Bautista J.*}

Nos hemos puesto en el papel de sondear, sobre un elemento poco esquivo para su análisis, el deporte. No porque este, no sea susceptible de ser analizado, sino por su cromatizarse, de acuerdo con sus necesidades y características.

Hemos visto su proceso dentro de nuestra sociedad, hemos convivido con una inmensa predeterminación pedagógica que lo acompaña. Lo hemos sabido separar de otros hechos sociales, de los campos, de los terrenos, en fin de todos los espacios. Nos detenemos y observamos la violenta fuerza con la cual, arrasa a través de su propia construcción y, aun así, no lo hemos definido con claridad.

Sabemos de su poder para ser obedecido en todos los aspectos, gracias a sus dos grandes pilares, como lo plantea Maurice Baquet ${ }^{1}$, ser enseñado con método y dirigido con firmeza, para cumplir con su objetivo final, incrementar el rendimiento físico atlético con alto grado de eficacia.

Ello, me permite asegurar una posición acerca de estos dos elementos, cuyo fundamento está en sus propios contenidos, método y firmeza, el método es un camino y como tal debe ser recorrido con los conocimientos básicos, para que el tránsito sea el mas adecuado en el logro de la meta y firmeza es la rigurosidad, no solamente para disciplinar al individuo entrenado, sino para acercarse a las técnicas y conocimientos que nos brinda la ciencia, y ponerlas en su debido funcionamiento.

Es decir, quien quiera realizar el proceso de entrenamiento en el deporte debe saber de sus métodos y procedimientos con profundidad, acompañado de un constante estudio de dicho fenómeno.

Ahora bien, al continuar con el análisis me apoyo en un plantemiento de Bernard Jeu, quien al querer encontrar el significado de deporte "en las tensiones que este expresa" $2, y$ especialmente enfocarlo en los referentes de la violencia y de las sensaciones de muerte allí presentes, permite a los individuos que a el se acercan, (al deporte) tomarlo como una opción, y no, como una imposición, cuando se conocen sus virtudes y sus defectos, cuando se es autónomo.

En este punto, nos enfrentamos a un tema que se ha venido tratando, con algún asomo de cuidado, y dando apenas algunas puntadas, suficientes, para iniciar el discernimiento del asunto que nos ocupa. La consustancialidad de lo espectacular, o espectacularidad del deporte, y los posibles puentes pedagógicos con la teoría del entrenamiento deportivo.

Me parece pertinente, iniciar este análisis, con una corta reflexión nacida de un cuento de Eduardo Galeano. Realmente la profundidad de la reflexión estará dada por la visión del lector, aunque es parte de nuestra responsabilidad aclararla a lo largo de este escrito.

\section{La cultura del espectáculo}

\footnotetext{
${ }^{*}$ Profesor Facultad de Educación Física U.P.N.

${ }^{1}$ M. Baquet, Epistemología y antropología del deporte, pág. 76.

${ }^{2}$ B. Jeu, Epistemología y antropología del deporte, pág. 71.
} 
Fuera de la pantalla, el mundo es

una sombra indigna de confianza.

antes de la televisión antes del cine, y era así.

cuando Búfalo Bill agarraba algún indio distraído y

conseguía matarlo, rápidamente procedía a arrancarle

el cuero cabelludo y los plumajes y demás trofeos y

de un galope llegaba desde el lejano oeste a los

teatros de New York, donde el mismo representaba la

heroica gesta que acababa de protagonizar. Entonces

cuando se abría el telón y Búfalo Bill alzaba

su cuchillo ensangrentado en el escenario, a la

luz de las candilejas, entonces ocurría, por primera

vez ocurría, de veras ocurría, la realidad ${ }^{3}$.

\section{"El deporte ese espectáculo",}

Es fundamental, partir de una premisa. El deporte sin espectadores no sería lo que es, ya que, su espectacularidad es lo que le confiere su estructura, su unidad "está hecho para ser visto", y el análisis que aquí se presenta basado en el dossier número tres de la cita cuatro, tiene dos elementos fundamentales, lo diacrónico y lo sincrónico, extrapolados de la cotidianidad cultural a la cual se ha arraigado el deporte, como en su momento explica J. M. Brohm "el deporte es, fundamentalmente, una arqueología de mitos. Como conjunto de representaciones colectivas, el deporte se ha convertido en un sistema sólidamente estructurado y coherente de mitos" ${ }^{25}$.

Esta estructura se ha conformado básicamente por dos aspectos, que son consustanciales a la exhibición del hecho deportivo, su carácter sincrónico, es decir la perfecta armonía temporal de sus componentes en el momento de ser expuesto, y como realizan su influjo de poder subyacente sobre los espectadores, y el carácter diacrónico, es decir todo lo que acompaña en su construcción a través del tiempo y a lo largo del mismo.

Esa exhibición, tomada desde su origen etimológico, ex-hibiere, es sencillamente sacar fuera de, y al ser sacada necesita ser observada, convirtiéndose en un fenómeno transitivo y expresivo en el tiempo; transitivo al ser observado, y expresivo porque precisamente produce, sensaciones emociones, o por lo menos eso intenta. Ahora bien, se puede producir a partir de dicho fenómeno, el nacimiento de una estética de la actividad deportiva, determinada, por la "solvencia corporal" de los actores, pero también por el tipo de elementos técnicos, tácticos que desarrolle; es allí donde esta labor del entrenador desde su dimensión pragmática, pasando por la dimensión cognitiva y de alguna manera aterrizando en la dimensión olística, puede construir a partir de los elementos que conoce y domina.

En el campo de las sensaciones, existe un elemento trágico en el deporte, y se hace necesario especialmente para el espectador, aquí se ha denominado "la muerte jugada", enmarcada en el límite que se le presenta al actor para realizarla, en el tiempo, en unas disciplinas más que en las otras, pero nunca ausente.

\footnotetext{
${ }^{3}$ Galeano, Eduardo, Ed, Siglo XXI, El libro de los abrazos, Bogotá, 1990, pág. 138.

${ }^{4}$ Barreau, J. Morne, J. Epistemología y antropología del deporte. Alianza Editorial, Madrid 1991.

${ }^{5}$ Brohm, J., M., Sociología política del deporte, Ediciones, Fondo de cultura económica. México 1982, pag. 229.
} 
Siempre se espera del deportista su entrega hasta el final, su sacrificio hasta el borde de la muerte. Es un acierto leer a J. M. Brohm cuando dice: "el sentido y el gusto del esfuerzo en el deporte se ha desarrollado en un sistema de la muerte, en una cultura de impulsión hacia la muerte. El deporte está estrechamente ligado a las representaciones mortíferas. Es el representante por excelencia de los impulsos de la muerte. El deporte es entonces, de alguna manera, el cementerio de la energía humana productiva, así como el cementerio es el museo de la muerte y de los muertos. Pero al mismo tiempo el deporte es una defensa contra la angustia de la muerte, como lo dice B. J. Jeau, el deporte es muerte simbólica, y violencia ritual. Ya que jugándosela se le conjura, se le domina y se le exorcisa. B. Jeau también dice: La muerte jugada es también el riesgo de la vida"6. Lo que hace el deporte es ponerla en escena, pero esa representación, necesita de una preparación, y de un entrenamiento, los cuales deben ser guiados, si, guiados con el debido conocimiento, de la causa y de sus posibles consecuencias, pedagógicas, sociológicas, políticas, etc.

M. Bernard, le confiere dos elementos a esta estética: la dramatización y la teatralización, la primera hace referencia al acto mismo, y la segunda a los elementos, o recursos de la teatralidad corporal explotada por el actor (léase deportista).

Otro aspecto de la puesta en escena, y de la cual se vale el deporte para dictar sus leyes, es la violencia. Este ingrediente planteado por N. Elias, muestra la diferencia entre, violencia contemporánea y violencia "legítima" de la antigüedad. Es de aclarar que, los juegos de competición de la antigüedad clásica, a menudo representados como el gran paradigma del deporte, tenían ciertas características propias y se desarrollaron en condiciones muy distintas de las de nuestros deportes. La ética de los jugadores, las normas por los cuales eran juzgados, las reglas de la competición y la realización propiamente dicha de aquellos juegos diferían notablemente en muchos aspectos de las características del deporte moderno ${ }^{7}$. Hemos visto, no hasta la saciedad, pero lo hemos palpado, que uno de los ideales del deporte es lograr ser identificado con aquellas antiguas actividades griegas, y ser reconocido como el fenómeno que cambiará el contexto social. Pero un solo vistazo a las normas de "pruebas", perdón de juegos de la antigüedad nos muestran, que los grados de violencia si que son bien diferentes, así como la interpretación que se les daba en ese momento histórico, un ejemplo lo encontramos en el boxeo y la lucha antigua, donde la cantidad de violencia física difícilmente sería aceptada en nuestro tiempo. Es el caso del pancration modalidad de lucha que reglamentaba lo siguiente: "en el pancration los contendientes luchaban con todo su cuerpo, con las manos, los pies, los codos, las rodillas, el cuello y la cabeza; en Esparta usaban incluso los dientes. Los pancratiastas podían sacarse los ojos uno al otro... También estaba permitido hacer caer al contrario echándole la zancadilla, asirlo por los pies, la nariz y las orejas, dislocarle los dedos de las manos, los huesos de los brazos y aplicarles las llaves de estrangulamiento. Si uno lograba derribar al otro, podía sentársele encima y golpearlo en la cabeza, el rostro, las orejas; también podía darle patadas y pisotearlo. No hace falta decir que en este brutal torneo los luchadores recibían en ocasiones las heridas más horribles y no pocas veces alguno resultaba muerto. El más brutal de todos era probablemente el pancration de los epheboi espartanos. Cuenta Pausíanas que los luchadores peleaban literalmente con uñas y dientes, se mordían y se vaciaban los ojos el uno al otro ${ }^{8}$.

\footnotetext{
${ }^{6}$ Brohm, J., M., op. cit. Pág. 274.

${ }^{7}$ Elias, N., El deporte como problema sociológico, pág. 164.

${ }^{8}$ Mezoe, F., Geschichte der olympischen, Munich. Citado en El deporte como problema psicológico, Elias, N., pág. 169. 
Aquí, se me ocurre una pregunta tal vez, ya respondida o susceptible de responder en el escrito, lo importante es hacerlo con sinceridad. Si el pancration, por ejemplo necesitaba de una preparación, y los demás juegos corporales, tenían como fin la preparación para la guerra ¿Cual es la diferencia con el entrenamiento de nuestros días?

Aterrizando todo lo anterior, en el ámbito del espectáculo, y tomando este como una característica propia del deporte, en últimas lo que se busca es fascinar la mirada del espectador. Ese que puede asistir a cualquier acto público, o social y vivirlo a su manera. Extrapolando de otro espectáculo como es el teatro, Hocquenghem y Scherer plantean que "la espectacularidad, es algo más que la mentira convencional del teatro, hace a lo esencial de la vida. Lejos de dejarse absorber por el teatro lo desborda. Generalmente se considera la espectáculo escénico una condensación, una dramatización, una simbolización de aquello que en la vida real no correspondería a lo espectacular... Llevado por su impulso el espectáculo se vuelve canalización, válvula de seguridad, instrumento cultural de poder...

El hecho de introducir o no la participación del espectador no altera en absoluto el marco general donde lo teatral se vuelve punto de encuentro y de las pulsaciones de una sociedad dominada y reglamentada"9. ¿Es igual en el deporte? A cosa difícil de responder ¿No? Sobre todo cuando estamos fascinados.

Esa fascinación, es la que lleva al espectador, a una especie de fantástica de la sensación, y con esto, está casi todo dicho. Allí el espectáculo hace resucitar el mito y materializar los rituales, uniendo las sensaciones de actores y espectadores. Desarrolla una interdependencia única, así sea mediata o duradera, hace que las emociones se compartan sin ningún intermediario, como lo dice Magnane ${ }^{10}$, se realiza en pleno la "simbiosis afectiva", la cual lleva al espectador a saberse sus opiniones de memoria, en lo concerniente al espectáculo deportivo, al actor, que digo actor deportista de turno, al equipo de sus afectos, es entonces, cuando prestan una gran ayuda los medios de comunicación, ya que sin ellos el poder de penetración del deporte no sería tan profundo. Los medios opinan por el espectador.

Los medios y el espectáculo mismo, han desarrollado un idioma propio, un lenguaje específico, tan especial que es inmune a la crítica por parte del mismo espectador, si en dado caso éste alcanza a vislumbrar el deporte tal como es, un espectáculo social, una conmemoración diacrónica de nuestras debilidades y potencialidades y una conmemoración sincrónica de nuestros afectos entrenados; de nuestras ilusiones. Este fenómeno se produce gracias a un elemento insustituible en el deporte, su carácter de imprevisible, de incierto; de lo que lleva a otro interrogante. Ya que el deporte se enseña a sus anchas en todos los estratos de nuestra sociedad y de una forma tan especializada. ¿Cuál es el papel del espectáculo deportivo en la sociedad contemporánea? Y por ende ¿cuál es el papel del entrenamiento deportivo?

Muchas personas se han dedicado a responder estas preguntas, y respuestas hay tantas como autores. Sigue siendo nuestra tarea el contestarnos el interrogante, sin ambages, sin miedos, sin convencimientos efímeros, con la condición única de la constante exploración de la realidad, y el apoyo de las ciencias, de todas, es decir sin dejar a un lado el espectáculo del estudio.

\footnotetext{
${ }^{9}$ Hocqueghem, G., Sherer, R. El alma atómica, Ediciones Gedisa, 1986, pág, 188.

${ }^{10}$ Magnane, Epistemología y antropología del deporte.
} 
Sin embargo debemos tener en cuenta lo que dice Dumazedier "no se puede impedir a la gente soñar; ni siquiera a que pague por ejercer ese derecho".

Encontraremos respuestas que nos llenarán de sueños, de héroes, de mitos de superhombres, de imperios que ya nos gobiernan. De supedeterminaciones y coartadas pedagógicas, para darle un sentido educacional al "hecho". La tarea es quitarse la venda, sin cortarse las venas, es tan simple como cruzar la línea y determinar, de qué lado se está, sin dejar de percibir todo el panorama, dejar la posibilidad del paso de ida, o de vuelta. El hecho deportivo es un hecho social gigantesco, tiene todas las características para fascinarnos.

\section{Se pone en escena \\ Es bello y auténtico Tiene códigos \\ Hace "participar" al espectador.}

Se debe reconocer que es realmente una profesión subyugadora, con todos los componentes de vida útil y jubilación, es decir, para entenderlo debe ser tratado como un fenómeno individual y en relación directa con las propuestas sociales que le son inherentes, para que sea estudiado sin pasiones que lo eleven al paroxismo, o lo deriven hacia el infierno.

Se han llegado a instancias tales como la de ridiculizar el hecho deportivo para hacerlo más mundano, más mío, donde incluso el espectador se sienta protagonista, (léase lucha libre) es impresionante, es allí donde se ve que "hay mucho espectáculo dentro de la sociedad y aún más dentro de la sociedad deportiva", espectacularidad dada por el rito que rodea al hecho deportivo, medición y preparación del tiempo, la ansiedad de la espera, el juez, el decorado general, para producir en última instancia, lo que quiere el espectador, ver a su ídolo, a ese ente familiar, conocido (sobre todo por sus destrezas), hacerse parte de él pero hasta determinado punto, pues como casi todos los ídolos, tiene pies de barro y cuando se cae, aparece la decepción y lastimosamente aunque no está en el libreto, (¿o sí está?) hay que cambiarlo para que siga el espectáculo.

Otra particularidad del hecho, perdón, del espectáculo está en su carácter épico, es una batalla en la cual no se sabe quien será el ganador, y si el triunfo se logra por muy poco margen el éxtasis del espectador, hincha, fanático curioso o como se llame, es mayor Es decir en un tiempo determinado se vive una historia en la que se conoce un vencedor y un vencido y que se rompe siempre con el rito presencial de un pito o de una bandera a cuadros. Allí se determina la batalla.

Esa gesta humana, u homínida plagada de folclorismos, de gestos compartidos en lo más público, si el término es válido, y en lo más clandestino de la simbiosis, es el deporte, es el espectáculo reelaborado constantemente, y para ello, hay que reelaborar la destreza de los movimientos que le dan origen, los arquetipos mentales de la perfección, en la destreza deportiva. En el acto del entrenamiento.

Para finalizar, y expuestos a los bostezos con la boca cerrada, como lo escuché hace poco en un seminario. A manera de reelaboración de la reflexión, el siguiente fragmento de Humberto Eco.

"Si el deporte (practicado) es salud, como el comer, el deporte visto es falseamiento de la salud. Cuando veo jugar a otros, no hago nada sano, y únicamente me deleito vagamente con la salud de los otros ( que ya sería escuálido ejercicio de boyerismo, como 
quien observa no a dos seres humanos, sino a dos abejas que hacen el amor; en espera de asistir a la muerte del zángano).

Es cierto que quien observa la práctica del deporte en otros se exita, grita y se remueve, y por lo tanto realiza una gimnasia física y psíquica, y reduce su agresividad y disciplina su competitividad. Pero esta reducción no es compensada, como en la práctica del deporte, por un acrecentamiento de energía y por la adquisición de control y dominio de si mismo, ya que los atletas rivalizan por juego, pero los voyeurs lo hacen en serio (tan cierto como es que luego se pegan un tiro o mueren por infarto en las gradas)" 11 .

De todas estas elucubraciones, siempre he tenido la sensación de la persecución, si, es como una carrera de pesadilla donde por mas que te mueves sientes que no lo haces, tal vez por la visión y los ejemplos.

Por la visión, ya que se debe estar en algún lado de la línea posicionando un sentir, una ideología, y por supuesto unos sueños, un sentir que permita al profesional de la actividad corporal denominada deporte y/o educación física determinar con claridad los derroteros de su campo de acción, sin miedos ni riesgos innecesarios, con la medida de lo conocido y el ansia de lo desconocido, siendo transparentemente autónomo, en el campo moral así la moral sea cuestión de geografía' como dice Facundo Cabral, y también en el intelectual. Una ideología acorde con sus principios que permita dar dirección al aprendizaje hacia las necesidades del individuo, teniendo en cuenta sus intereses y mostrando los riesgos y beneficios de ese proceso de aprendizaje, implicaciones que ella conlleva, por ser una ciencia prescriptiva, pero fundamental y necesaria hasta para la reconstrucción de los sueños, sí de los sueños que son susceptibles de realizar en busca de seres humanos con proyectos de vida enmarcados dentro o fuera del deporte, pero siempre pletóricos de movimiento, y así fomentar el proyecto de hombre, con las calidades y cualidades necesarias para un proyecto de sociedad.

Es en este punto donde la teoría del entrenamiento deportivo cumple un papel de inmensa importancia, convirtiéndose en un modelo de aplicabilidad y construcción pedagógica, por ser concreto y con objetivos específicos como el rendimiento o la consecución de la forma deportiva a través de procesos sistemáticos, organizados y controlados por el individuo. La tarea es salirnos de los terrenos del rendimiento deportivo o, realizar un trabajo serio dentro del mismo. Así este rendimiento se podrá transferir a la posibilidad cotidiana de ser eficaz, si bien es cierto que en algunos ámbitos del deporte el atleta simplemente es eficiente, el proceso nos muestra que si se hacen las cosas con la responsabilidad y el conocimiento adecuado, de la decisión final recaerá siempre en un ser humano que siente, que piensa, que actúa y se comunica por sus propias experiencias y realizaciones es decir, un deportista autónomo.

Si no logramos hacer de la actividad deportiva, un goce inherente a lo sacro como en la antigüedad, por los menos debemos acercarla a una ejecución pensada de los condicionantes del hombre, que sea una exacerbación del músculo nacida del deseo y el conocimiento consciente. Que los riesgos sean tomados a partir de análisis de los principios y leyes que rigen el entrenamiento deportivo. El fomento de una profunda reflexión y adecuación de los saberes, para entender los procesos y permitirnos la formulación de teorías propias, nacidas de dicha reflexión, puede llegar todas las didácticas del mundo, pero si no están aterrizadas en una "pedagogía individual", (léase filosofía de la vida) estaremos supeditados a repetir acciones, que quizá nos provean de resultados, pero serán tan efímeros que no vale la pena sustentarlos.

\footnotetext{
${ }^{11}$ Eco, Humberto. La estrategia de la ilusión. Ediciones Lumen, 1986, pág. 242. 
Eso es una filosofía personal, con la posibilidad de ser una filosofía social y como tal debe ser atendida, así nos suceda lo que dice Monod.

Resulta imprudente hoy en día, por parte de un hombre de ciencia, emplear la palabra "filosofía", aun siendo "natural" en el título (o incluso el subtítulo) de una obra. Se tiene la seguridad de que será acogida con desconfianza por los científicos y, a lo mejor, con condescendencia por los filósofos. No tengo mas que una excusa, pero la creo legítima: El deber que se impone, hoy más que nunca, a los hombres de ciencia es considerar a su disciplina dentro del conjunto de la cultura moderna, para enriquecerla no solo de conocimientos técnicos importantes, sino también de las ideas salidas de su ciencia, que pueden considerarse humanamente significativas. La ingenuidad misma de una visión nueva (la de la ciencia siempre lo es) puede a veces iluminar con un nuevo día antiguos problemas $^{12}$.

Soy el punto de partida y de llegada. Soy el puerto, y el barco, y la mar Soy todo y nada, pero siempre encuentro refugio en mi.

ENTRE EL SER Y EL DEBER DE SER DE LA AUTORIDAD EN EL DEPORTE

${ }^{12}$ Monod, J., El azar y la necesidad, Ediciones Planeta, 1970, pág. 10. 